\title{
MANUAL SMALL INCISION CATARACT SURGERY (MSICS)
}

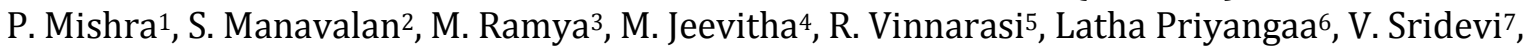
R. Parth ${ }^{8}$

\section{HOW TO CITE THIS ARTICLE:}

P. Mishra, S. Manavalan, M. Ramya, M. Jeevitha, R. Vinnarasi, Latha Priyangaa, V. Sridevi, R. Parth. "Manual Small Incision Cataract Surgery (MSICS)". Journal of Evolution of Medical and Dental Sciences 2014; Vol. 3, Issue 46, September 22; Page: 11249-11261, DOI: $10.14260 /$ jemds/2014/3467

ABSTRACT: In developing country like India, the primary goal is to provide all the benefits to common man at minimal possible cost in visual rehabilitation of cataract. In achieving this goal, the surgery (MICS) described in this article can be extremely helpful. It has almost all the advantages of phacoemulsification, at the same time it is inexpensive. The wound construction, various techniques of nucleus delivery in MSICS are described precisely. This may stimulate the reader towards this surgery, which is the only way to tackle the huge backlog of cataract in developing countries, particularly in India, where $60 \%$ of rural people live in less than thirty rupees a day.

KEYWORDS: MSICS, SICS, Non-Phaco, Capsulorrhexis, Microvectis, Cataract Surgery.

INTRODUCTION: Good quality vision is one of our prized possessions. One of the basic human rights is the right to see. Surveys have shown that sight is the sense that people fear losing. ${ }^{1.2}$ Vision problems are common among older adults. In the west, the average age of cataract onset is about 60 years, whereas in developing countries like India, cataract (Fig 1) occurs frequently even at 45 years of age. ${ }^{3}$ Decreased vision due to cataract; clouding of human crystalline lens is a major cause of concern and important public health issue, especially in developing countries, since it is responsible for $47.8 \%$ of world total blindness. ${ }^{4}$

According to a recent update by World Health Organization (WHO), 285 million people are estimated to be severely visually impaired worldwide, of which around 39 million are blind. ${ }^{5}$ Cataract is believed to be the major cause of blindness, ${ }^{6-8}$ accounting overall, for about 50\%. ${ }^{9}$ More than $95 \%$ of the backlog of cataract blind is found in the developing countries.

For visual rehabilitation, cataract surgery is the most common surgical procedure performed on these patients. Major advancements in surgical and lens technology have led to an enormous increase in surgical volume because of the improved safety profile and outcomes. Overall, over the years, major advances in cataract surgery are Phacoemulsification and Manual Small Incision Cataract Surgery (MSICS). In other words modern cataract surgery is basically of two types, machine dependent Phacoemulsification, and machine independent Manual Small Incision Cataract Surgery (MSICS). Despite major technological advances in the treatment of cataracts, the greatest challenge continues to be the large and increasing back log of cataract blindness. It is estimated that 3.8 million people will develop cataract every year in India, as against 2.7 million cataract surgeries done every year. ${ }^{10.11}$

Phacoemulsification has several limitations including the high cost of equipment and maintenance and the requirement for intensive surgical training. ${ }^{12}$ In addition, there are concerns regarding the amount of energy released at the probe tip and its effect on non-target tissues leading to iris, capsule, corneal and other structural damage such as phaco burn, endothelial cell loss and other injuries. 
Further, for the more advanced and mature cataracts, which is common in the Indian population, performing phacoemulsification becomes more difficult and complication prone, finally one has to spend 200 -600 \$ or more for this surgery. Keeping all these in mind, question arises "Is quality affordable?" Can a person who lives on less than $1 \$$ per day afford a high quality cataract operation? About $60 \%$ of rural India lives on less than Rs. 35.00 a day, reported by the National Sample Survey Organization (NSSO) in 2012.13 If the answer is no to the above questions, then do we offer that person poor or low quality services? ${ }^{14}$

Do people living in poverty have a right to high quality eye or health care? If the answer is yes, then this could probably be accomplished by MSICS. In this procedure (MSICS), following a peri bulbar or subtenon's block, through a capsulorrhexis, superior or temporal self-sealing 5.50-7.00 mm sclera tunnel incision, manual or automated cortical cleanup, a PMMA IOL is implanted either in the bag or sulcus.

Several methods are described and various names given for example Manual Small Incision Cataract Surgery (MSICS), mini nuc-technique, manual phaco, non phaco for machine independent small incision cataract surgery. In 1983, Gerald Keener JR (Table 1) pioneered the alternative method of small incision cataract extraction, snare technique of MSICS to divide the nucleus before its removal. ${ }^{15}$ It was for the first time the lens was removed through a $6 \mathrm{~mm}$ incision without the use of Phacoemulsification. This article analyses the different techniques of nucleus removal during MSICS.

\begin{tabular}{|c|c|c|c|}
\hline Year & Technique & Place & Surgeon \\
\hline $800 \mathrm{BC}$ & Couching & India & Susruta \\
\hline $1015 \mathrm{AD}$ & Needle aspiration & Iraq & Unknown \\
\hline 1100 & Needle aspiration Couching & Syria & Unknown \\
\hline 1500 & Couching & Europe & Unknown \\
\hline 1745 & ECCE inferior incision & France & Daviel \\
\hline 1753 & ICCE by thumb expression & England & Sharp \\
\hline 1860 & ECCE superior incision & Germany & Von Graefe \\
\hline 1880 & ICCE muscle hook zonulolysis and lens tumble & India & Smith \\
\hline 1900 & ICCE by capsule forceps & Germany & Verhoeff \\
\hline 1940 & ICCE by capsule suction erysiphake & Europe & Barraquer \\
\hline 1949 & ECCE with post. chamber IOL, operating microscope & England & Ridley \\
\hline 1951 & Anterior chamber IOLs & Italy & Strampelli \\
\hline & & Germany & Daneheim \\
\hline 1957 & ICCE by enzyme zonulolysis & Spain & Barraquer \\
\hline 1961 & ICCE by Cryo extraction & Poland & Krawicz \\
\hline 1967 & ECCE by Phacoemulsification & USA & Kelman \\
\hline 1975 & Iris- pupil supported IOLs & Netherland & Binkhorst, \\
\hline 1980 & Posterior/Scleral tunnel incision & USA & Kratz, Girard, and Hoffmann \\
\hline 1983 & Snare technique(MSICS) & USA & Gerald T Keener \\
\hline 1984 & Foldable IOLs & USA & Mazzocco \\
\hline & & South Africa & Epstein \\
\hline 1984 & Capsulorrhexis & Canada & Howard Gimbel \\
\hline & & Germany & Thomas Neuhan \\
\hline 1984 & Phacosandwich (MSICS) & USA & Luther Fry \\
\hline 1985 & Phacosection (MSICS) & USA & Peter Kansas \\
\hline 1986 & Cataract refractive surgery & USA & Various \\
\hline 1991 & Frown incision & USA & J A Singer \\
\hline 1991 & Hydrodissection, hydroexpression, MSICS & Israel & Blumenthal \\
\hline 1992 & Phaco chop (phacoemulsification) & Japan & K Nagahara \\
\hline 1993 & Topical anaesthesia & USA & Fishman \\
\hline 1997 & Fish hook technique (MSICS) & Nepal & A Hennig \\
\hline 2002 & Microvectis (MSICS) & India & P Mishra \\
\hline
\end{tabular}


Wound Construction: MSICS has distinct advantages over other forms of cataract surgery in terms of wound stability, reduced surgical trauma and associated complications, minimal astigmatism and early rehabilitation.

\section{The construction of sclerocorneal tunnel in MSICS consists of the following Steps:}

1. External Scleral Incision.

2. Sclerocorneal Tunnel.

3. Internal Corneal Incision.

4. Side Port Paracentesis.

External Scleral Incision: Kratz ${ }^{16}$ in 1980, was the first surgeon to move the cataract incision from limbus to sclera, increasing the surface of the apposed wound. This was expected to enhance wound healing and to lessen surgically wound induced astigmatism. Girard and Hoffmann ${ }^{17}$ in 1984 were the first to call it the scleral tunnel incision.

a. Location of Incision: In MSICS, the incision is made 1-3 $\mathrm{mm}$ behind the limbus over the sclera either superiorly or in the temporal aspect.

\section{b. Style of External Incision}

i. Frown Incision.

ii. Straight Incision.

iii. Curvilinear/ Smile Incision.

iv. Chevron or Inverted V Shaped Incision.

v. Blumenthal Side Cut.

i. Frown Incision (Fig.2): difficult to make with minimal induced astigmatism. ${ }^{18}$ If the ends of the external incision are placed further superior/ away from limbus on the sclera, then the incision becomes more stable. The superior wound edge acts as though there are slings hanging down which are supporting the ends of the incision. As a result the inferior edge of the incision would not sag away from the superior edge of the incision.

The potential for against the rule astigmatism virtually disappears. Jack A Singer ${ }^{19}$ in 1991 called it frown incision, where each end of the incision is further away from the sclera and produces least amount of astigmatism. He described frown incision, which was a modified pocket incision, curved opposite to the limbus. In a series of 62 eyes he compared the astigmatism for frown incision group with scleral pocket incision group and found that frown incision group consistently had a lower standard deviation from the mean induced astigmatism than the scleral pocket incision group.

ii. Straight Incision: moderate induced astigmatism: Kratz ${ }^{20}$ in 1980, was the first surgeon to move the cataract incision to sclera. Straight incision as the name suggests is a straight line incision about $2 \mathrm{~mm}$ away from limbus, two extreme points of the incision are secured in the sclera and the inferior edge, directly adjacent to these end points of the incision cannot sag, so induced astigmatism is limited to the degree of instability of the middle of the incision.

This type of incision induces moderate astigmatism, lesser than that of curvilinear type. A straight incision of smaller length induces less astigmatic change, if it is in the incisional funnel. A longer incision has to be moved posterior to achieve the same effect. 
Mc Farland ${ }^{21}$ in 1989 introduced an incision architecture that is self-sealing. He observed that the scleral tunnel wounds appeared to be water tight before the placement of a suture and that horizontal suture actually caused bleeding in some cases. Tying the suture knots seemed to distort the scleral tunnel and thus caused slight leakage. He hypothesized that if the following conditions were met, the wound could be self-sealing:

1. The incision started far behind the surgical limbus.

2. The sclera tunnel was kept very narrow.

3. Vertical cuts were made in the floor of the scleral tunnel to give a spreading effect, much like an accordion.

iii. Curvilinear Incision/ Smile Incision: Easy to make, but results in increased astigmatism. ${ }^{18}$ Smile incision is a curvilinear incision over sclera which runs parallel to limbus, similar to traditional cataract incisions. With this incision there is nothing to prevent the inferior edge from falling away from the superior edge. This wound gape (sliding) is the potential cause for against the rule astigmatism. This induces high astigmatic changes as the wound is unstable and prolongs the visual rehabilitation of the patient.

iv. Chevron or Inverted V Shaped Incision: Difficult to make, difficult manoeuver ability with least induced astigmatism. In 1990, Pallin ${ }^{22}$ described a chevron shaped incision. In 1991, he used it in 700 eyes. It is based on the same principle as the frown incision. The incision is given in the form of the inverted letter ' $V$ ', the apex of the $V$ is near the limbus and the limbs are away from it. Pallin (1991), analyzed inverted $v$ shaped cataract incision with scleral tunnel entry into anterior chamber in 700 eyes and pointed out that the fulcrum in the crotch of $\mathrm{V}$ provides easier access to the anterior chamber for instrument manipulation. However, this incision is quite difficult to make, the tunnel size in this incision is relatively smaller, and hence manoeuvring a large nucleus through this would be difficult.

v. Blumenthal Side Cuts: large pocket tunnel, minimal induced astigmatism. Blumenthal ${ }^{23}$ side cuts was devised by Michel Blumenthal in 1993.This incision has a straight line and two oblique cuts at its two ends. This increases the space in the tunnel for easy delivery of nucleus, popularly known as scleral pocket tunnel. In 1994, he also propagated use of continuous positive pressure in the anterior chamber using the anterior chamber maintainer (ACM) with good surgical results.

Sclerocorneal Tunnel: Basically there are two types of approach.

a. Superior (12 o' clock) Tunnel.

b. Temporal Tunnel.

a. Superior (12 o' clock) Tunnel: Wound construction plays a major role in MSICS, where everything about the wound has to be carefully planned depending on the type of technique, hardness of nucleus, amount of astigmatism and the condition of the epithelium. Richard Kratz(1980) ${ }^{16}$, created the scleral pocket incision by making a partial thickness groove in the sclera about $2 \mathrm{~mm}$ behind the limbus and then tunnelling, anteriorly to enter the peripheral anterior chamber on the corneal side of the trabecular meshwork. 
The concept of incisional funnel was postulated by Paul Koch in 1991. It deals with certain characteristics of self-sealing incisions like length and external configuration that impart not only self-sealing but also astigmatism neutrality to these incisions. Mechanics of external incisions can be understood if we consider that astigmatism is inversely proportional to the distance of the incision, placed from the limbus. The composite relationship between astigmatism, length of incision and distance from the limbus can be projected on ocular surface, producing so called incisional funnel.

It consists of an imaginary pair of curved lines representing the outer limits of scleral incision that produces the same amount of astigmatism. These lines diverge outwards from limbus, separating as the distance from the limbus increases. Incisions made within this funnel will, for all practical purposes, be astigmatically neutral. Accordingly smaller incisions made closer to the limbus and larger ones further away, will all have the equivalent effect on corneal curvature.

\section{The scleraocorneal tunnel has six aspects ${ }^{24}$ :}

i. Size (length).

ii. Shape.

iii. Depth.

iv. Width.

v. Entry to anterior chamber.

vi. Location.

i. Size or Length of external incision is the distance between two ends of the incision not along the contour of incision. It varies from 5-6 mm for cortical cataract, and from 6-7 mm for nuclear sclerotic grade IV cataract. The external scleral groove is initiated by the Bard Parker knife with no 15 blade or with a diamond knife. Paul Ernest in 1990 studied the astigmatism induced by $12 \mathrm{~mm}, 7 \mathrm{~mm}$ and $4 \mathrm{~mm}$ incisions. At 3 months postoperatively he noticed 3.09D astigmatism with $12 \mathrm{~mm}, 1.92 \mathrm{D}$ with $7 \mathrm{~mm}$ and 1.05D with $4 \mathrm{~mm}$ incisions, which was reduced to 1.32D and $0.99 \mathrm{D}$ respectively at 8 months follow up. This shows that the amount of astigmatism is less with smaller incisions compared to longer ones.

ii. Shape (Style) of incision was discussed earlier. Usually frown or straight external incisions are preferred; its anterior limit is $2-3 \mathrm{~mm}$ behind the limbus. The sclerocorneal tunnel is dissected with a crescent blade. It should be uniform in thickness and extended up to 1-1.5 mm into clear cornea.

iii. Depth is defined as thickness of flap. The optimal depth for the scleral flap is $0.2-0.3 \mathrm{~mm}$, which can be accurately measured using a guarded, calibrated diamond knife held perpendicular to the scleral surface, or else $1 / 2$ to $2 / 3$ rd thickness of sclera is usually taken into account. ${ }^{25}$ Very thin flaps may create two problems. First, they have a tendency to tear or button hole formation with manipulation and second, the induced astigmatism will be high due to slippage of scleral flap. With thicker flap, there is a higher risk of premature entry resulting in iris prolapse and hyphaema.

iv. Width has been defined as the distance between external scleral incision and line of entry into the anterior chamber (internal entry). It has been found out that when the external groove is placed as far posterior as possible, induced astigmatism is minimal.

v. Entry to anterior chamber 
This is performed using a sharp 2.8 or $3.2 \mathrm{~mm}$ angled keratome. The bevel of the keratome is lifted at the anterior limit of the tunnel and dipped to create a dimple. Once the tip is entered, keratome blade is reoriented, parallel to iris plane and then advanced. During extension of the incision, care should be taken to keep in the same plane, and one should cut as the keratome enters into anterior chamber. Blumenthal advocates inner lip should be parallel to the limbus and not a horizontal line. It is the integrity of internal corneal lip that imparts selfsealing nature to this incision. Inner corneal lip should extend almost up to the limbus but should not cut the limbus on either side.

vi. Location. Sclerocorneal tunnel can be made either superiorly at 12 o' clock position or in the temporal aspect. As the cornea flattens along the meridian of the scleral section, incision can be fashioned in the steep meridian of the pre-existing astigmatism. In patients with preoperative against the rule astigmatism, the temporal site can be preferred. While fashioning a temporal tunnel, it is advisable to dissect it more anterior into the cornea before entering into anterior chamber as the cornea is horizontally oval in shape and as such temporal limbus is narrower.

b. Temporal Tunnel: In MSICS, the following situations are indicated for temporal approach of scleraocorneal tunnel:

a. Pre-existing against the rule astigmatism.

b. Presence of superior filtering bleb.

c. Deep socket eyes where superior tunnel construction and other manipulations are difficult to carry out.

d. Secondary procedures where previous surgical manoeuvres have left behind scarred tissue superiorly. e.g., aphakic eyes requiring secondary implants, intraocular lens exchange etc.

Principle and techniques of temporal tunnel are the same. The orientation of the microscope and the surgeon are shifted towards the temporal side of the eye that is to be operated. Since surgical limbus has width of only $0.4 \mathrm{~mm}$ in the horizontal meridian, lamellar dissection into cornea should be more anterior in order to get a better valve effect of self-sealing incision. The side port is made more inferiorly at 7 o' clock position.

Side Port Paracentesis: Two side ports (paracentesis) are made using 15 degree knife or MVR blade or with $20 \mathrm{G}$ hypodermic needle in the clear cornea on either sides. The stab entry is done parallel to iris and is $2 \mathrm{~mm}$ wide. Most surgeons preferred this for capsulorrhexis and bimanual irrigation and aspiration of cortex. Through the side port viscoelastic is injected to make the eye ball firm to allow easy entry of keratome blade. It also helps in completion of the extension of wound as the anterior chamber is entered. At the end of surgery it is useful to reform the anterior chamber.

Anterior Capsule Management: Anterior capsulotomy is one of the most critical steps in scleral tunnel extracapsular cataract extraction. Secure long term capsular fixation and centration of posterior chamber intraocular lens can be best achieved if integrity of the central opening is maintained. Radial tears that extend towards the equator from the margin of the capsulotomy are associated with a high incidence of extrusion of at least one haptic out of the capsular bag, resulting in tilting and decentration of the intraocular lens. 
Capsulorrhexis: The advent of continuous curvilinear capsulorrhexis (CCC) by Howard Gimbel and Thomas Neuhan 26 in 1990 revolutionized the small incision cataract surgery. It results in improved IOL centration in the bag. It may decrease the rate of posterior capsule opacification, when biconvex, or posterior convex lenses are used. They pointed out that it prevents post-operative iris contact with anything except the lens capsule, which is more posterior postoperatively.

It prevents the development of posterior synechia between the iris and the capsule. If an inadvertent posterior capsule tear occurs, a posterior chamber IOL can easily and safely be implanted in the ciliary sulcus anterior to the intact rim of CCC. It provides a safe method of IOL implantation in patients with uveitis, in which stable endocapsular IOL fixation is essential to decrease uveal contact and irritation. Gimbel and Neuhann in 1991, proposed a slight change in the nomenclature from continuous circular capsulorrhexis to continuous curvilinear capsulorrhexis, thus preserving the CCC abbreviation, because opening in the anterior capsule may not be a perfect circle.

\section{NUCLEUS MANAGEMENT:}

1. Viscoexpression: Krag et al. in 1990, evaluated the technique of nucleus delivery with visco and hydroexpression in cadaver eyes and concluded that visco expression was a safe and easier technique of nucleus delivery. They stressed the need of a large anterior capsular opening. Corydon and Thim in 1991, explained the concept of hydro and visco expression of the nucleus with the help of specially designed bent cannula for nucleus delivery through a continuous circular capsulorrhexis.

Bellucci et al. in 1994, in their study of 142 eyes concluded that visco expression of the nucleus through a large capsulorrhexis, $7 \mathrm{~mm}$, was the best method of surgery. They observed that visco expression was successful in 93\% cases.

Korynta in 1996, performed visco expression in 369 eyes and reported that relaxing capsular incision was required in $17.1 \%$ cases. The most frequent complication in cases without relaxing incision was asymmetric implantation of IOL, sulcus bag (2\%). In cases with relaxing incision, the most frequent complication was posterior capsule rupture (7.9\%). Bourton and Pickering in 1995, performed SICS in a series of 162 cases, using a limbal incision and delivered nucleus successfully by visco expression in $87.7 \%$ eyes. There were 5 cases of zonular dehiscence, one of posterior capsule rupture, and two of vitreous prolapse.

2. Hydroexpression: Blumenthal and Moisseiev in 1987, described the use of anterior chamber maintainer $(\mathrm{ACM})^{23}$ for maintaining a deep anterior chamber during surgery. They observed that ACM keeps the pressure in anterior chamber at uniform levels during various manoeuvres, thus making the technique safer and easier to perform. Blumenthal in 1994, propagated the use of continuous positive pressure in anterior chamber using the ACM with good surgical results.

3. Phaco Sandwich Technique: Luther Fry first attempted the Phaco sandwich technique in 1985. He was actually trying to bisect the nucleus inside the anterior chamber. He was using a standard lens loop and an iris spatula/ IOL dialer. In the process he discovered that by squeezing the nucleus between these two instruments, it could be extracted through a smaller wound, leaving softer peripheral nuclear and cortical matter in the eye for later aspiration. The safety and effectiveness of this surgical technique, depends heavily on viscoelastic materials.

Once vectis is in position, Sinskey hook (IOL dialer) is carefully placed on top of the nucleus, sandwiching it between these two instruments. 
4. Fish-hook Technique: Hennig27 et al. in 2003, reported a series of 500 eyes in which MSICS was performed with nucleus delivery using fish hook technique. The technique involved sclerocorneal tunnel, capsulotomy, hydrodissection, nucleus extraction with a bent needle tip hook, posterior chamber IOL implantation. The best corrected visual acuity was $6 / 18$ or better in $96.2 \%$ of eyes at 6 weeks and in 95.9\% at 1 year. Intra-operative complications included 47 (9\%) eyes with hyphaema, one eye with posterior capsular tear and vitreous in the anterior chamber. Six weeks postoperatively, $85.5 \%$ eyes had against the rule astigmatism, with mean induced cylinder of 1.41D (SD 0.8).

5. Irrigating Vectis: The technique of nucleus extraction with an irrigating vectis was described by Nishi in 1986, the technique uses a combination of mechanical and hydrostatic forces to express out the nucleus. After prolapsing the nucleus into the anterior chamber viscoelastic was injected both above and below the nucleus. The upper layer shields the endothelium while the lower layer pushes the posterior capsule and iris diaphragm posteriorly.

This creates space for insertion of the irrigating vectis. The superior rectus suture is loosely held in the left hand or the assistant is asked to hold it. The vectis is now tested outside for patency of ports. Once confirmed it is then insinuated concave side up, under the nucleus. One should again confirm and make sure that the margin of vectis is seen through the nucleus. This is possible in most cataracts except mature white and black nuclei. Then the superior rectus is pulled tight and with the globe thus fixed, the irrigating vectis is withdrawn out slowly without irrigating till the superior pole of the nucleus is engaged in the tunnel.

The irrigation is now started and vectis slowly withdrawn out while pressing down on the scleral lip. These steps are crucial in protecting the endothelium. The irrigation keeps the anterior chamber well-formed whereas the downward pressure also helps to prevent the nucleus from touching the endothelium. The force of irrigation has to be reduced when the maximum diameter of nucleus just clears the tunnel. This step prevents the nucleus being thrown out forcefully with a consequent sudden decompression and shallowing of anterior chamber.

6. Phaco Fracture: A small incision has distinct intraoperative and postoperative advantages. Phacofracture is the manual nuclear fragmentation for removing a large nucleus through a small incision. Peter Kansas introduced the technique. He bisected the nucleus in the anterior chamber using a sharpened cyclodialysis spatula. Phacofracture is possible by the following methods:

a. Bisector technique.

b. Trisector technique.

c. Wire loop (Snare) technique.

d. Pre chop technique of Akahoshi modified by Bhatti.

a. Phacofracture with Bisector: A solid curve vectis, at least $4 \mathrm{~mm}$ at its greatest width and approximately $8 \mathrm{~mm}$ in length is insinuated under the nucleus after injecting viscoelastic. The bisector is carefully introduced and positioned on the anterior surface of the nucleus. Two instruments are manoeuvred towards each other. The bisector will gradually cleave its way through the nuclear substance and stops when it comes in contact with the vectis. Steady and constant pressure on the bisector and gentle lifting pressure with the vectis will easily split the nucleus into two pieces. With proper positioning of the two instruments, one of the 
fragments is sandwiched and then brought out. The anterior chamber is reformed with viscoelastic, which is used not only to deepen the anterior chamber but also to reposition the remaining fragment centrally so that it can be readily grasped and extracted from the anterior chamber.

b. Phacofracture with Trisector: This technique is based on the principle of sectioning the nucleus in the anterior chamber into three small pieces before delivering them out one by one. Nucleus after being prolapsed into anterior chamber, the solid vectis is insinuated under the nucleus taking care that it does not go under the iris. The trisector is passed over the nucleus keeping well away from the endothelium. The trisector is passed downwards towards the vectis cutting the nucleus into three pieces. Each piece can then be extracted out with the help of serrated forceps or by sandwich technique.

c. Wire loop (Snare): This technique was introduced by Gerald Keener in 1983. He designed a nuclear snare which resembled and functioned like a tonsillar snare. He made it basically from 18-19 gauge blunt tipped needles and a 32 gauge stainless steel wire. After prolapsing the nucleus into anterior chamber the wire loop is positioned around the nucleus. Viscoelastic is used liberally. The loop is now shortened by pulling it back. This causes the loop to cheese wire through the nucleus and divide into two. Each piece can then be delivered out one at a time with the help of forceps.

d. Prechop technique of Akahoshi modified by Bhatti: Bhatti in 2009 described the modified prechop technique of Akahoshi. In the original Akahoshi technique, he had described the pre chopping of nucleus into four quadrants in the capsular bag with a single handed technique using a cross-action forceps with pointed tips and flat blades. Bhatti first dislocated the nucleus into anterior chamber and then chopped from behind forward. Therefore, there was no pressure on the zonules. To prevent endothelial damage, a dialer or similar instrument was pressed into the nucleus from above, thus stabilizing it for the chop.

7. Microvectis Technique: Several techniques are described above for nucleus management in MSICS for example: hydro-expression, visco-expression, phaco-sandwich, phaco-fracture, irrigating vectis etc, but Microvectis (Lens Loop) is our preferred technique. Microvectis ${ }^{25}$ (Fig.3) is not an irrigating vectis. It is a small lens loop (4-5 mm) with a long handle without having irrigating ports. Long handle provides good grip and is very useful to apply sufficient tangential pressure during delivery of large nuclei. There is no need to pull/retract the superior rectus bridle suture while delivering the nucleus.

After reforming the anterior chamber with viscoelastic, the superior pole of the nucleus is engaged, lifted up and rotated with the help of an IOL dialer or 26G bent needle and subsequently prolapsed into the anterior chamber. Once the superior pole is lifted up, viscoelastic is injected underneath to make nucleus rotation easy. The nucleus rotation is done either clockwise, anticlockwise or both to luxate the nucleus completely into the anterior chamber. Whenever the nucleus would not subluxate into the anterior chamber from the capsular bag, re- hydro dissection or hydro 
delineation are tried to overcome the difficulties. This difficulty is quite often seen in soft cataracts. Same problem is encountered when the rhexis is small, here; relaxing incision is given over the anterior capsule to facilitate nucleus subluxation. Sometimes in hypermature morgagnian cataract, Simcoe's cannula with irrigation on is insinuated under the nucleus to flip up one of its pole into the anterior chamber, and subsequently rotated.

Once the nucleus is in the anterior chamber, viscoelastic is placed both anterior and posterior to it. This step is essential to avoid endothelial damage during nucleus delivery and to get clear transparent cornea in the immediate post-operative period (Fig.4). A microvectis is introduced underneath the nucleus, which is expressed by applying forward (tangential) pressure while depressing the posterior scleral lip. This step is performed in a controlled fashion under direct visualization to avoid trauma to cornea and iris. Whenever anterior chamber becomes shallow while introducing microvectis, it is reformed with viscoelastic through the side port during this procedure.

Cortex Removal: The cortical remnant is easily removed either by automated irrigation and aspiration system or Simcoe's cannula. Cortex, including 12 o'clock is safely and easily managed by automated bimanual I/A system. Visco-expression is sometimes carried out by injecting viscoelastic into anterior chamber $(\mathrm{A} / \mathrm{C})$ in a controlled manner while depressing the posterior scleral lip to remove cortical matter. Anterior chamber maintainer is never used during surgery in our set up.

Lens Implantation and Closure: A single piece PMMA lens 5.5 to $6 \mathrm{~mm}$ optic diameter is implanted through the incision after injecting viscoelastic material. Viscoelastic is aspirated by bimanual I/A at the end. The anterior chamber is reformed with air or balanced salt solution. The wound is tested for any leakage from the paracentesis, if any, is hydrated by intrastromal injection of irrigating fluid. The conjunctiva is approximated by injecting subconjunctival steroid injection over the conjunctival flap.

CONCLUSION: MSICS is most commonly done cataract surgery in India, because it is inexpensive. Different types of wound construction and nucleus management are described very precisely. Out of all techniques, authors advocate a simple, innovative Microvectis technique. It will be of great help to ophthalmologist as well as post graduate students in ophthalmology to clear the huge backlog of cataract in India.

\section{REFERENCES:}

1. Royal Institute of Blind. Survey reveals nation's fear of sight loss. The Institute, 2008; www.rnib.org.uk/xpedio/groups/public/documents/publicwebsite.accessedNovember 12, 2008.

2. Americans fear losing their sight more than other physical impairments. Market Wire, October2000; http://www.find articles.com/p/articles, accessed November 12, 2008.

3. Vyas RT. Social aspect of cataract. In: Lim ASM, Jones, editors. Vision: World's Major Blinding Conditions. Singapore: Fespic Enterprises; 1982. p 4-9.

4. Resnikoff S, Pascolini D, Etya'ale D. Global data on visual impairment in the year 2002. Bull World Health Organ 2004; 82:844-51.

5. Pascolini D, Marriotti SP, Global estimates of visual impairment: 2010. Br J Ophthalmol 2012; 96: 614-18. 
6. Venkatsamy G. Cataract in Indian subcontinent. Ophthalmic Surg1987; 18: 464-66.

7. Steinkuller PG. Cataract: The leading cause of blindness and vision loss in Africa. Soc Sci Med 1983; 17: 1693-702.

8. Thylefors B, Resnikoff S. Progress in the control of blindness and future prospective. Sante 19988: 140-43.

9. Schwab L. Cataract blindness in developing countries. Int Ophthalmol Clin 1990; 30: 16-18.

10. Minassian DC, Mehra V. 3.8 million blinded by cataract each year: projection from the first epidemiological study of incidence of cataract blindness in India. Br JOphthalmol 1990; 74: 341-43.

11. Jose R. National programme for the control of blindness. Indian J comm. Health 1997; 3:5-9.

12. Chang DF. Tackling the greatest challenge in cataract surgery (editorial). Br J Ophthalmol 2005; 89: 1073-74.

13. NSSO, Dept of Statistics, India, 68 ${ }^{\text {th }}$ Survey, July 2011-June2012, $1^{\text {st }}$ Aug 2012.

14. Lindfield R, Foster A, Is quality affordable? Community Eye Health J 2008; 21: 53-55.

15. Gerald TKJ. The nucleus division technique for small incision cataract extraction. In: George WR, Aziz MY, Axis MD, editors. Alternative small incision technique.Thorofare, N.J.Slack inc.1990 p163-95.

16. Kratz RP, Colvard DM, Mazzocco TR, et al. Clinical evaluation of the terry surgical keratometer. Am Intraocular Implant Soc J.1980; 6: 249-51.

17. Girard LJ, Hofmann RF. Scleral tunnel to prevent astigmatism. In: Emery GM, Jacobson AC, editors. Current concepts in cataract surgery, Proceeding of the eight biennial cataract surgical congress. Norwalk. Appleton-Century- croft.1984 pp101-02.

18. Haldipurkar SS, Shikari HT, Gokhale V. Wound construction in manual small incision cataract surgery. Indian J Ophthalmol 2009; 57: 9-13.

19. Singer JA. Frown incision for minimizing induced astigmatism of small incision cataract surgery with rigid optic intraocular lens implantation. J Cataract Refract Surg.1991; 17: 677-88.

20. Kratz RP, Colvard DM, Mazzocco TR, et al. Clinical evaluation of the terry surgical keratometer. Am Intraocular Implant Soc J.1980; 6: 249-51.

21. Mc Farland M. Mc Farland surgical technique. In: Gills JPM, Sanders DR editors.Small incision cataract surgery: Foldable lenses, one stitch surgery, sutureless surgery. Thorofare, N.J: Slack Inc; 1990. pp 107-16.

22. Pallin SL. Chevron sutureless closure: a preliminary report. J Cataract Surg.1991; 17: 706-09.

23. Blumenthal M. Askenzi I, Fogel R, et al. The gliding Nucleus. J Cataract Refract Surg 1993; 19: 435-37.

24. Sachdev MS, Mishra P, Thanikachalam S. The manual small incision: surgical aspect-1. In: Small incision cataract surgery (Manual Phaco) $2^{\text {nd }}$ edition, (1 $1^{\text {st }}$ edition 2002) Singh Kamaljeet editor. Jaypee Highlights Medical. Inc. 2010. New Delhi pp77-84.

25. Mishra P, Vasudevan R, Krishnaram $\mathrm{K}$ et al. Manual small incision cataract surgery, our experience with microvectis technique. Indian J Intraocular implant Refract Soc 2007;3:18-23.

26. Gimbel HV, Neuhann T. Development, advantages and methods of the continuos circular capsulorrhexis technique.J Catarct Refract Surg 1990; 16: 31-37.

27. Hennig A, Kumar J, Yorston D et al. Sutureless cataract surgery with nucleus extraction: outcome of a prospective study in Nepal. Br J Ophthalmol 2003; 87: 266-70. 


\section{ORIGINAL ARTICLE}

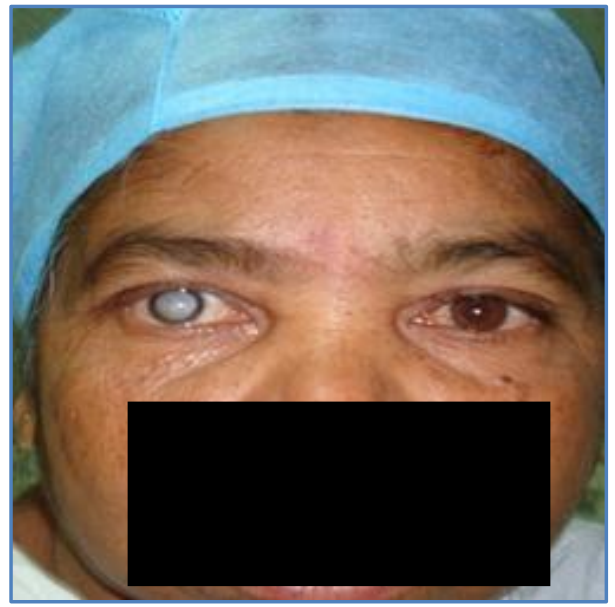

Fig. 1: Image showing Senile Mature Cataract

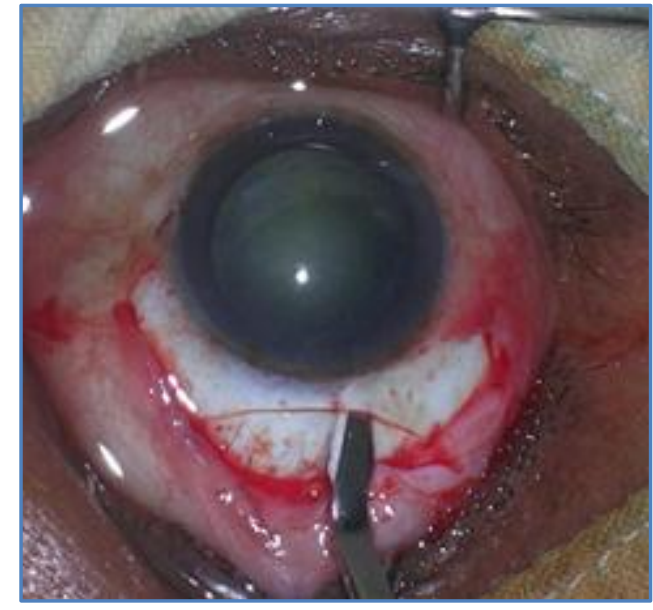

Fig. 2: Image showing Frown Scleral Incision

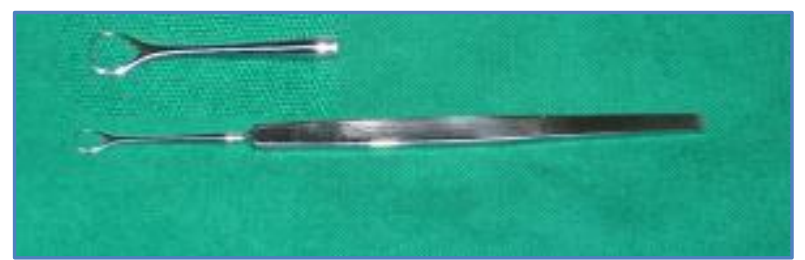

Fig. 3: Microvectis

(Lens Loop)

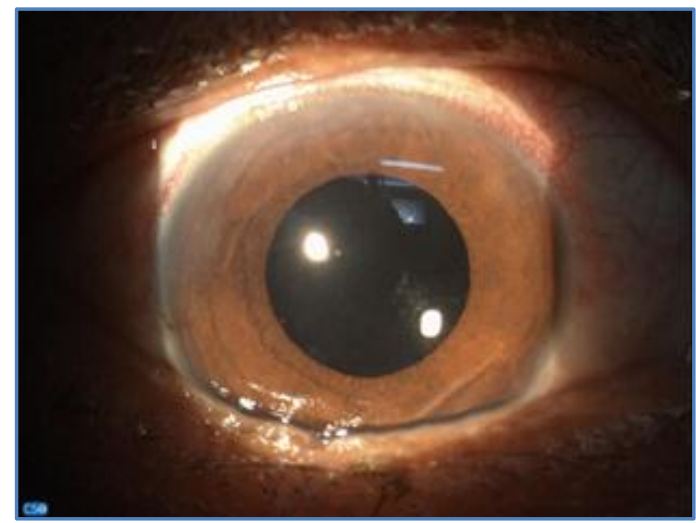

Fig. 4: Post-operative Slit lamp Image of patient Fig. 1, Showing Crystal clear cornea 


\section{ORIGINAL ARTICLE}

\section{AUTHORS:}

1. P. Mishra

2. S. Manavalan

3. M. Ramya

4. M. Jeevitha

5. R. Vinnarasi

6. Latha Priyangaa

7. V. Sridevi

8. R. Parth

\section{PARTICULARS OF CONTRIBUTORS:}

1. Professor and HOD, Department of Ophthalmology, RMMCH, Annamalai University.

2. Professor, Department of Ophthalmology, RMMCH, Annamalai University.

3. Tutor, Department of Ophthalmology, RMMCH, Annamalai University.

4. Post Graduate, Department of Ophthalmology, RMMCH, Annamalai University.

5. Post Graduate, Department of Ophthalmology, RMMCH, Annamalai University.
6. Post Graduate, Department of Ophthalmology, RMMCH, Annamalai University.

7. Reader, Department of Ophthalmology, RMMCH, Annamalai University.

8. Post Graduate, Department of Ophthalmology, RMMCH, Annamalai University.

\section{NAME ADDRESS EMAIL ID OF THE CORRESPONDING AUTHOR:}

Dr. P. Mishra,

Professor and HOD,

Department of Ophthalmology, RMMCH,

Annamalai University-608002,

Tamilnadu.

Email: drpmishra1@gmail.com

Date of Submission: 06/09/2014.

Date of Peer Review: 08/09/2014.

Date of Acceptance: 15/09/2014.

Date of Publishing: 20/09/2014. 